\title{
The development of a strategy for improving low-power gas turbine engines
}

\author{
Igor Ivanov, ${ }^{1, *}$ \\ ${ }^{1}$ Don State Technical University, Rostov-on-Don, Russian Federation
}

\begin{abstract}
This article presents the author's method of developing an original design solution for low-power gas turbine engines based on the TIPS-FCA system obtaining a patent for a method and a device.
\end{abstract}

\section{Introduction}

For a long period of time, functional-cost analysis (FCA) has been used effectively all over the world to improve the design parameters of various technical systems.

In our country, FCA was effectively used in conjunction with TIPS (theory of inventive problem solving) in TIPS-FCA systems to improve various technological processes.

Currently, in the global practice, the FCA has also begun to be used widely for economic calculations and solving strategic problems.

The article describes the application of the functional-synergetic method based on TIPSFCA to develop a strategy for improving low-power gas turbine engines. [1,2].

\section{Urgency}

American companies are the main competitors for microturbines and low-power turbines that began to widely introduce developed turbines in various fields of activity. Recently, due to the depreciation of the ruble, the cost of American microturbines has increased sharply (more than by 2 times) and their purchase has become impractical consequently it is necessary to develop domestic microturbines with similar American parameters, but at a lower cost and for using them completely to produce thermal and electric energy and for technological processes, especially in agriculture. Microturbines are not massively produced in Russia.

\section{Statement of the problem}

Low power gas turbine units as autonomous energy sources are widely used in various fields of activity. That is why, in all highly developed countries, large-scale research is carried out to increase the efficiency of gas turbines using various methods. Among these methods, the most effective is the steam-gas cycle (STIG process), in which water vapor is

\footnotetext{
* Corresponding author: igoriv740@yandex.ru
} 
supplied to various parts of the gas turbine plant: into the combustion chamber, in front of the low pressure turbine and in front of the power turbine. [3]. At gas turbine power plants of the Aquarius type through the use of the STIG process, the efficiency is increased by 5.9 $\div 13 \%$, and power by $43 \div 130 \%$ for gas turbine engines of different capacities [4].

Objective: how to implement the STIG process in a low-power gas turbine plant in order to obtain a greater effect at the minimum cost of the process.

\section{Theoretical part}

Functional Synergetic Method

If the system is composed of I elements, with the cost of each element - $\mathrm{Ci}$, then the cost of the system function is:

$$
C=A \sum C i
$$

where $\mathrm{A}$ is the coefficient of transformation of the functions of the elements into a function of the system.

$\mathrm{F}$ is the value of the function of the system, which is usually determined by expert means or by profit from the resulting process of the system.

The effectiveness of the synergistic action of the system - E can be estimated by the proportion of $\mathrm{F}$ and $\mathrm{C}$.

when E $>1$-positive synergistic effect,

$$
E=\frac{F}{C},
$$

when $\mathrm{E}<1$-negative synergistic effect.

When developing systems with a synergistic effect, it is necessary to get:

$$
E=\frac{F}{C} \rightarrow M A X
$$

The initial elements of the system: hydrocarbon fuel, air and water.

The resulting process of the system: the effective operation of a gas-vapor mixture with a minimum content of harmful emissions. Reducing manufacture costs, increasing durability.

\section{Analysis of analogues}

On the basis of the analysis of the working process in combustion chamber, it is reasonable to supply water to the inner surface of the combustion chamber. In this case, water performs two functions: it cools the wall and contributes to the intensification of the steam-gas cycle, but for this it is necessary to ensure the stability of the water membrane on the surface of the chamber. On the basis of patent analysis, a well-known solution was found due to the rotation of the combustion chamber, which is practically hard to implement.

\section{TIPS Elements}

To solve this problem, we will make up technical contradictions (TC):

TC-1. In order for water to perform two functions: cooling the wall and contributing to the intensification of the steam-gas cycle, water must be supplied to the inner surface of the combustion chamber, but for this it is necessary to ensure the stability of the water membrane on the surface of the chamber due to its rotation which is very hard and expensive. 
TC-2 When supplying water in the form of steam, there is no need to ensure the stability of the water membrane on the surface of the chamber, but water does not perform the function of cooling the chamber wall.

We will take TC-1 as a basis as it corresponds to the determined goal.

The development of a new strategy.

For perfection of this process, the author has developed and patented a new method for supplying water to the combustion chamber [5]

The technical task of the claimed invention is the creation of a thin-walled layer of an aqueous liquid on the inner surface of the combustion chamber to reduce the temperature of the vapor-gas mixture and to increase its amount.

The technical result of the proposed technical solution is to enlarge efficiency, increase the duration of a gas turbine plant and reduce harmful emissions during its operation. [6,7]

The above mentioned problem is solved in the following way: aqueous liquid is directed tangentially to the inner surface of the combustion chamber and acts on the aqueous liquid by means of the guide wall. As aqueous liquid one can use water, water with water soluble additives, water-alcohol solution and water-fuel compositions.

In the device for implementing the claimed method of operation of a gas turbine plant containing a combustion chamber with air and fuel supply systems for the combustion process and a water supply system to the inner surface, the outlet of the pipeline for supplying aqueous liquid is directed tangentially to the inner surface of the combustion chamber, into the cavity formed by the inner surface of the chamber combustion, the outer surface of the guide wall and the end wall connecting these surfaces.

The technical essence of this invention is illustrated in Figure 1, which shows a scheme of the construction of a gas turbine plant for implementing the proposed method of operation of a gas turbine plant.

A gas turbine plant comprises a combustion chamber (1), in which a burner (2) is located, into which fuel (3) and air (4) are supplied from a compressor (5); aqueous liquid (6), which is supplied from the pump (not shown) through the pipeline (7) for supplying the aqueous liquid tangentially to the inner surface of the combustion chamber (1) into the cavity (8) formed by the inner surface of the combustion chamber (1), the outer surface of the guide walls (9) and end walls (10) connecting these surfaces; a gas-vapor mixture chamber (11) in which a gas turbine (12) is located, connected through a compressor (5), a reducing gear (13) with an electric generator (14); (15) - vapor-gas mixture to the recovery boiler, (16) - air from the atmosphere, (17) - air with water and vapor exhausts.

A gas turbine unit operates in the following way: air from the atmosphere (16) is sucked into a compressor (5), where it is compressed and supplied to the burner (2), where fuel is also supplied to (3) and the combustion process occurs on the surface of the burner in the combustion chamber (1) where the aqueous liquid (6) enters, through the pipeline (7) tangentially to the inner surface of the combustion chamber into the cavity (8) formed by the inner surface of the combustion chamber (1), the outer surface of the guide wall (9) and the end wall (10) joining these surfaces.

Meanwhile, a wall layer of liquid is formed on the inner surface of the combustion chamber, which moves coaxially and tangentially at the same time, rotating in the direction towards the base of the burner(2).

As a result, due to the interaction of the centrifugal force of the aqueous liquid and hightemperature radiation of the flame, two phases of the aqueous liquid will be formed: liquid, adjacent to the inner surface of the combustion chamber and steam, which will be sucked into the flame, providing reduction of harmful emissions and partial conversion of fuel with the formation of hydrogen and its combustion, which will increase the efficiency of the plant. 
$[8,9]$. Using a water-alcohol mixture or a water-fuel composition, this effect will be enhanced. [10].

Gases from the combustion chamber (1) enter the gas-vapor mixture chamber (11), where they impact the gas turbine (12), which rotates the compressor (5) and, through the gearbox (13), the electric generator (14).

Due to the heating and vaporization of the aqueous liquid, the temperature of the vaporgas mixture decreases, which enables to reduce the compressor power and thus to increase the efficiency and to prolong the duration of the turbine.

From the turbine, the gas-vapor mixture (15) is supplied to a waste heat boiler (not shown in the figure), which operates according to the author's patent [5], and the air, with water vapor and exhaust gas components (17), is supplied from this waste heat boiler to a compressor (5).

Thus, the proposed method of operation of a gas turbine plant, with the proposed design of a device for supplying water to the combustion chamber, allows to organize an effective combined cycle, which provides high efficiency with a low content of harmful emissions and increases the duration of a gas turbine.

\section{Claim}

1.The method of operation of a gas turbine plant by supplying air, fuel and water to the combustion chamber to the surface of the combustion chamber, featuring in the way that the aqueous liquid is directed tangentially to the inner surface of the combustion chamber and impacts this liquid by the guiding wall, and one can use water with water-soluble additives, a water-alcohol solution, and water-fuel composition as aqueous liquid.

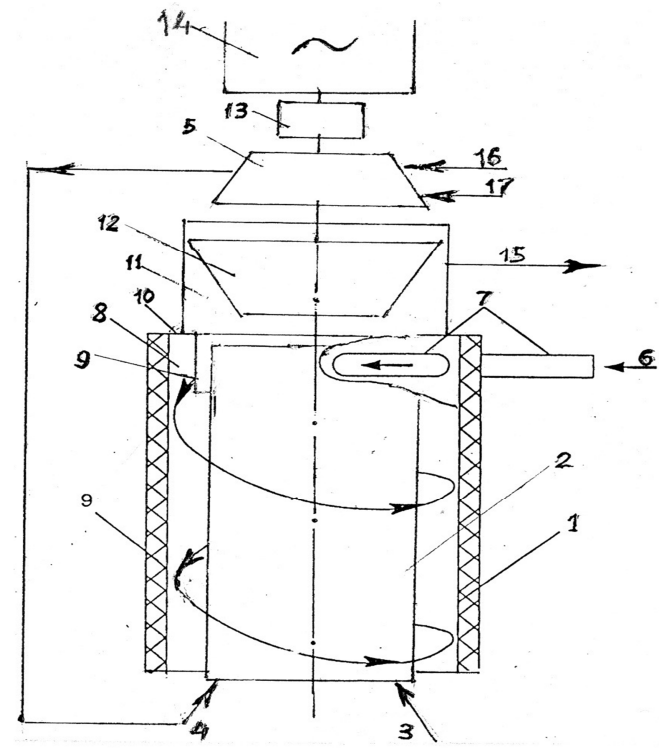

Fig. 1 The basic design scheme of gas turbine plant

2. A device for implementing a method of operating a gas turbine plant with an internal steam-gas cycle, comprising a combustion chamber with an air and fuel supply system for the combustion process and a water supply system to the inner surface of the combustion chamber, featuring in the way that the outlet of the pipeline for supplying a watercontaining liquid is directed tangentially to the inner surface of the combustion chamber 
into the cavity formed by the inner surface of the combustion chamber, the outer surface of the guiding wall and the end wall connecting these surfaces, and the surface guiding wall which impacts the aqueous liquid runs parallel with the inner surface of the combustion chamber.

\section{Conclusion}

1. The proposed strategy based on TIPS-FCA enables to develop designs of complex systems, particularly microturbines for various fields of activity.

2. The proposed technology of the process of internal cooling of the combustion chamber and decreasing the temperature of the gas-vapor mixture enables to increase the duration of the microturbine and to reduce the requirements to materials for the combustion chamber and turbine which can reduce the manufacturing cost.

3. The developed process allows to use various types of fuel and their composition, which enable to use microturbines in various regions and in different fields of activity.

\section{Reference}

1. I.A. Ivanov, A.N. Kuleshov, Alukhanyan Functional cost analysis in machine building (2011)

2. I.A. Ivanov, G.E. Persiyanova, Interagromasch (2015)

3. I.A. Ivanov, V South Russian forum "Power Efficiency Economy" (2010)

4. I.A. Ivanov, I.V. Avlasenko, E.V. Gatsenko, International scientific and technical journal, 2 (2018)

5. I.A. Ivanov, Patent of Russian Federation №2663830 F02C3/305. Issued on (10.08.2018). № 22 .

6. I.A. Ivanov, L.M. Avlasenko, Interagromasch (2017)

7. I.A. Ivanov, G.E. Persiyanova, Interagromasch (2018)

8. I.A. Ivanov, A.S. Zhuravlev, Interagromasch (2017)

9. A.S. Vasiliev, I.A. Ivanov, Interagromasch (2017)

10. A. Ivanov Patent for designing 2013147549. Application \# 2559055. Registered in Russian Federation roster on 10 July (2015) 